\title{
Achievement of specified lipid and high- sensitivity C-reactive protein levels with two statins in Chinese patients with hypercholesterolaemia
}

\author{
Cheng Ding ${ }^{1}$, Miao $\mathrm{Hu}^{2}$, Yong-Jian $\mathrm{Wu}^{1}$ and Brian Tomlinson ${ }^{2 *}$
}

\begin{abstract}
Background: Statins reduce plasma low-density lipoprotein cholesterol (LDL-C) and high-sensitivity C-reactive protein (hsCRP) levels. Rosuvastatin $10 \mathrm{mg}$ daily appears to be more potent in reducing LDL-C than simvastatin $40 \mathrm{mg}$, but the relative effect of these two statin doses on hsCRP is unknown.

Methods: Chinese hyperlipidaemic patients with high cardiovascular risk or familial hypercholesterolaemia (FH) were treated with rosuvastatin $10 \mathrm{mg}$ and simvastatin $40 \mathrm{mg}$ daily in an open-label crossover study. Lipid profiles were measured off treatment and after at least 4 weeks treatment with each of the two statins and hsCRP levels were measured on treatment with both statins.

Results: Both treatments were well tolerated in 247 patients (age $55.7 \pm 11.1$ years; 100 male; 140 with FH) with good treatment compliance. There were statistically significant differences $(P<0.001)$ for rosuvastatin versus simvastatin for LDL-C reduction $(-52.4 \pm 11.9 \%$ vs. $-47.7 \pm 10.8 \%)$ and on-treatment LDL-C $(2.62 \pm 0.99 \mathrm{mmol} / \mathrm{L}$ vs. $2.86 \pm 0.97 \mathrm{mmol} / \mathrm{L})$, respectively, but the on-treatment hsCRP levels $(1.33 \pm 1.37 \mathrm{mg} / \mathrm{L}$ vs. $1.41 \pm 1.57 \mathrm{mg} / \mathrm{L}, P>0.05)$ were not significantly different. The lipid target (LDL-C $<2.6 \mathrm{mmol} / \mathrm{L})$ was achieved by $52.9 \%$ with rosuvastatin compared with $42.6 \%$ with simvastatin $(P<0.05)$. The proportions of patients attaining hsCRP targets of $<2$ and $<1 \mathrm{mg} / \mathrm{L}$ were similar with the two statins (57.1\% and $74.6 \%$ for rosuvastatin vs. $57.1 \%$ and $80.1 \%$ for simvastatin, $P>0.05)$.

Conclusion: A significantly greater proportion of patients achieved LDL-C targets with rosuvastatin $10 \mathrm{mg}$ compared to simvastatin $40 \mathrm{mg}$ in Chinese patients with hypercholesterolaemia, but there was no significant difference in achieving hsCRP target levels with the two statins.
\end{abstract}

Keywords: High-sensitivity C-reactive protein, Statins, Low-density lipoprotein cholesterol, Chinese

\section{Introduction}

The significant cardiovascular benefits of statins have been proven in many large randomized clinical trials and these benefits are thought to be largely mediated by their effect on reducing plasma low-density lipoprotein cholesterol (LDL-C) concentrations. Other pleiotropic effects such as anti-inflammatory and anti-oxidative effects may also be involved $[1,2]$. These large clinical trials showed

\footnotetext{
* Correspondence: btomlinson@cuhk.edu.hk

An outline of this report was presented at the 80th European Atherosclerosis Society Conference in Milan, Italy, May 25-28, 2012.

${ }^{2}$ Department of Medicine and Therapeutics, The Chinese University of Hong Kong, Prince of Wales Hospital, Shatin, Hong Kong
}

Full list of author information is available at the end of the article that every $1 \mathrm{mmol} / \mathrm{L}$ reduction in LDL-C with statin therapy was associated with a proportional reduction of about $20 \%$ in major vascular events [3] and more intensive statin therapy with greater reductions in LDL-C of 2-3 mmol/L might reduce the incidence of major vascular events by $40-50 \%$ [4]. Based on this accumulated evidence, lipid guidelines have advocated lower LDL-C targets [5-7].

Inflammation plays a fundamental role in the pathogenesis of atherothrombotic disease $[8,9]$. Prospective observational studies showed that a raised concentration of high-sensitivity C-reactive protein (hsCRP), a wellknown and extensively studied systemic biomarker of 
inflammation, was associated with increased risk of vascular disease and mortality [10], although whether this association is causal or indicative of another underlying risk factor is still controversial [11]. Statin therapy reduces hsCRP levels in a wide range of patients and some studies demonstrated that patients who had lower hsCPR levels with statin therapy had greater clinical benefits [12-14]. The large JUPITER (Justification for the Use of statins in Primary prevention: an Intervention Trial Evaluating Rosuvastatin) study has shown that the reductions in LDL-C and hsCRP with rosuvastatin treatment were independent predictors of the vascular benefits of statin treatment and the reductions in LDL-C and hsCRP in individual patients were not significantly correlated suggesting that the change in hsCRP levels with statin is independent of the change in LDL-C [14]. The result of the JUPITER trial prompted the United States Food and Drug Administration to approve the use of rosuvastatin in subjects ( $>50$ years in men; $>60$ years in women) with elevated hsCRP levels $(>2 \mathrm{mg} / \mathrm{L})$ and at least one additional cardiovascular risk factor in early 2010 [15].

Simvastatin and rosuvastatin are two commonly used statins worldwide with the doses of $40 \mathrm{mg}$ simvastatin or $10 \mathrm{mg}$ rosuvastatin being commonly prescribed in Chinese patients with increased cardiovascular risk and higher levels of LDL-C. Lower doses of 2.5 and $5 \mathrm{mg}$ rosuvastatin are considered more standard in Japan and have been shown to slow coronary plaque progression [16], but higher doses are probably needed to produce regression of coronary plaque volume [17]. It has been shown that on average rosuvastatin $10 \mathrm{mg}$ daily has a more potent effect on reducing LDL-C than that of simvastatin $40 \mathrm{mg}[18,19]$, but there is no study comparing the effect of these two statins on hsCRP which may involve pathways which differ from those involved in lowering LDL-C. This study examined the LDL-C and hsCRP goal attainment with simvastatin and rosuvastatin in Chinese patients with hypercholesterolaemia.

\section{Methods}

This study analysed data from Chinese patients with hypercholesterolaemia who received both rosuvastatin and simvastatin in an open-label, crossover study performed to assess the pharmacogenetics of responses as described previously [18]. In brief, the study subjects were Hong Kong Han Chinese patients aged at least 18 years with established coronary heart disease (CHD) or CHD risk equivalent [6], including some with heterozygous familial hypercholesterolaemia $(\mathrm{FH})$. Individuals with uncontrolled diabetes, hypertension or thyroid disease, significant renal or hepatic dysfunction, those who had experienced a cardiovascular disease (CVD) event within the 3 months before recruitment, or those with poor adherence with statin therapy (reporting taking $<80 \%$ of the prescribed number of tablets) were excluded. There were 177 patients taking rosuvastatin $10 \mathrm{mg}$ daily and 70 patients taking simvastatin $40 \mathrm{mg}$ as initial treatment. Baseline and on-treatment lipid profiles and on-treatment hsCRP levels were measured after at least 4 weeks treatment for each statin. Thereafter, patients were switched to the other statin for at least 4 weeks with lipid and hsCRP levels being re-measured.

The study protocol was approved by the Clinical Research Ethics Committee and the study was performed in accordance with the Declaration of Helsinki. All participants gave their written informed consent.

\section{Laboratory analysis}

The lipid and laboratory safety parameters were measured by routine methods. The plasma hsCRP concentration was determined using an immunonephelometric method (Siemens Dade Behring CardioPhase hsCRP assay, Newark, DE, USA) on the Siemens BN ProSpec ${ }^{\circ}$ System with the detection limit of $0.146 \mathrm{mg} / \mathrm{L}$ (the measurement range was $0.146-9.35 \mathrm{mg} / \mathrm{L}$ ) and the inter-assay coefficients of variation of 2.5, 3.8 and $2.1 \%$ at hsCRP concentrations of $0.500,1.30$ and $2.10 \mathrm{mg} / \mathrm{L}$, respectively.

\section{Statistical analysis}

Subjects with hsCRP levels $>10 \mathrm{mg} / \mathrm{L}$ were excluded from the analysis for hsCRP $(n=13)$ as this high level of hsCRP is likely to be due to acute illness and for those with hsCRP levels below the limit of detection, the value of $0.1 \mathrm{mg} / \mathrm{L}$ was assigned. The on-treatment LDL-C and hsCRP levels with the two statins and the percentage change in lipids were compared by paired $t$-test or Wilcoxon test wherever appropriate. According to the Adult Treatment Panel III guideline, the overall LDL-C goal for high-risk patients is $<2.6 \mathrm{mmol} / \mathrm{L}$ with an optional intensified LDL-C goal of $<1.8 \mathrm{mmol} / \mathrm{L}$ for patients with very high-risk [7]. Subjects were evaluated as to whether they had attained the hsCRP goals of $<2 \mathrm{mg} / \mathrm{L}$ or $<1 \mathrm{mg} / \mathrm{L}$. The LDL-C and hsCRP goal attainments with the two statins were compared by using a $X^{2}$ test. $P$ value $<0.05$ was considered statistically significant. Data were analyzed with SPSS version 17.0 (SPSS Inc., Chicago, IL, USA).

\section{Results}

Both treatments were well tolerated in 247 patients with good compliance. The baseline characteristics of the study participants are shown in Table 1. There was no significant difference in baseline characteristics between subjects with different statin treatment orders (data not shown). The mean $( \pm \mathrm{SD})$ age of the study subjects was $55.7 \pm 11.1$ years and $40.5 \%(n=100)$ of the study 
Table 1 Baseline characteristics of the study participants

\begin{tabular}{lcccc}
\hline & All & Males & Females & $P$ \\
& $(n=247)$ & $(n=100)$ & $(n=147)$ & \\
\hline Age, years & $55.7 \pm 11.1$ & $55.0 \pm 11.0$ & $56.1 \pm 11.3$ & 0.425 \\
FH, $n(\%)$ & $140(56.7)$ & $53(53.0)$ & $87(59.2)$ & 0.336 \\
Hypertension, $n(\%)$ & $118(47.8)$ & $52(52.0)$ & $66(44.9)$ & 0.273 \\
Type 2 diabetes, $n(\%)$ & $48(19.4)$ & $24(24.0)$ & $24(16.3)$ & 0.135 \\
History of CVD, $n(\%)$ & $24(9.7)$ & $10(10.0)$ & $14(9.5)$ & 0.901 \\
Current smoker, $n(\%)$ & $26(10.5)$ & $24(24.0)$ & $2(1.4)$ & $<0.001$ \\
\hline
\end{tabular}

$C V D$, cardiovascular disease; $F H$, familial hypercholesterolaemia

subjects were male. There were 140 patients having $\mathrm{FH}$ who had significantly higher baseline levels of LDL-C and HDL-C but lower triglycerides than those of nonFH patients (Fig. 1).

There were significant differences $(P<0.001)$ for rosuvastatin versus simvastatin for the on-treatment LDL-C $(2.62 \pm 0.99 \mathrm{mmol} / \mathrm{L}$ vs. $2.86 \pm 0.97 \mathrm{mmol} / \mathrm{L}$, and the percentage reduction in LDL-C $(-52.4 \pm 11.9 \%$ vs. $-47.7 \pm 10.8 \%$ ), but not for the on-treatment hsCRP levels $(1.33 \pm 1.37 \mathrm{mg} / \mathrm{L}$ vs. $1.41 \pm 1.57 \mathrm{mg} / \mathrm{L}, P>0.05)$ in overall subjects and in subgroups of $\mathrm{FH}$ and non-FH patients, respectively (Fig. 2). Body weight and waist circumference were not different whilst on the two statin treatments (body weight: $64.1 \pm 13.1 \mathrm{~kg}$ with rosuvastatin and $64 . \pm 13.1 \mathrm{~kg}$ with simvastatin, $P>0.05$; waist circumference: $85.9 \pm 11.6 \mathrm{~cm}$ vs. $85.3 \pm 12.6 \mathrm{~cm}, P>0.05$ ).

The on-treatment LDL-C and the on-treatment hsCRP levels on rosuvastatin treatment were significantly correlated with the respective values on simvastatin $(r=0.812$ and $r=0.683, P<0.001$ for both), whereas there was no correlation between the on-treatment LDL-C level or the percentage reduction in LDL-C in response to either statin and the on-treatment hsCRP levels $(P>0.05)$. There was no difference in on-treatment LDL-C and hsCRP levels with the two statins in patients receiving the statin treatments in a different order of (data not shown).
The LDL-C targets of $<2.6 \mathrm{mmol} / \mathrm{L}$ and $<1.8 \mathrm{mmol} / \mathrm{L}$ were achieved by $52.4 \%$ and $20.3 \%$ with rosuvastatin compared with $43.3 \%$ and $9.8 \%$ with simvastatin in all subjects $(P<0.05)$. The difference in LDL-C goal attainment with the two statins was more significant in $\mathrm{FH}$ patients (Fig. 3). There were higher proportions of non$\mathrm{FH}$ patients achieving the LDL-C goals with both statins than $\mathrm{FH}$ patients, as $\mathrm{FH}$ patients had higher baseline LDL-C levels (Fig. 3). The proportions of patients attaining hsCRP goals of $<2$ and $<1 \mathrm{mg} / \mathrm{L}$ with the two statins or in patients with or without FH were not significantly different $(P>0.05)$ (Fig. 3).

There were $39 \%$ of patients achieving both targets for LDL-C of $<2.6 \mathrm{mmol} / \mathrm{L}$ and hsCRP $<2 \mathrm{mg} / \mathrm{L}$ with rosuvastatin treatment compared to $28.1 \%$ patients attaining both targets with simvastatin treatment $(P<0.05)$.

\section{Discussion}

With the advantage of comparing two treatments in the same subjects in a crossover design, this study showed that a significantly $(P<0.05)$ greater proportion of patients achieved LDL-C targets with rosuvastatin $10 \mathrm{mg}$ compared with simvastatin $40 \mathrm{mg}$ in this group of Chinese patients with increased cardiovascular risk. There were $81.1 \%$ and $72.6 \%$ of non-FH patients reaching the LDL-C level of $<2.6 \mathrm{mmol} / \mathrm{L}$ with rosuvastatin and simvastatin, respectively. However, in patients with $\mathrm{FH}$, lipid-lowering monotherapy with rosuvastatin and simvastatin only enabled $30.7 \%$ and $20.9 \%$ of patients to achieve the LDLC level of $<2.6 \mathrm{mmol} / \mathrm{L}$. Furthermore, there were no patients who achieved the LDL-C goal of $<1.8 \mathrm{mmol} / \mathrm{L}$ with simvastatin treatment compared with $7.1 \%$ who achieved it with rosuvastatin. These results suggest that higher statin doses or combination therapy is needed to reach LDL-C goals in Chinese patients with $\mathrm{FH}$, as in other ethnic groups [20].

In a parallel group study in Greek patients with hyperlipidaemia, rosuvastatin $10 \mathrm{mg}$ and simvastatin $40 \mathrm{mg}$

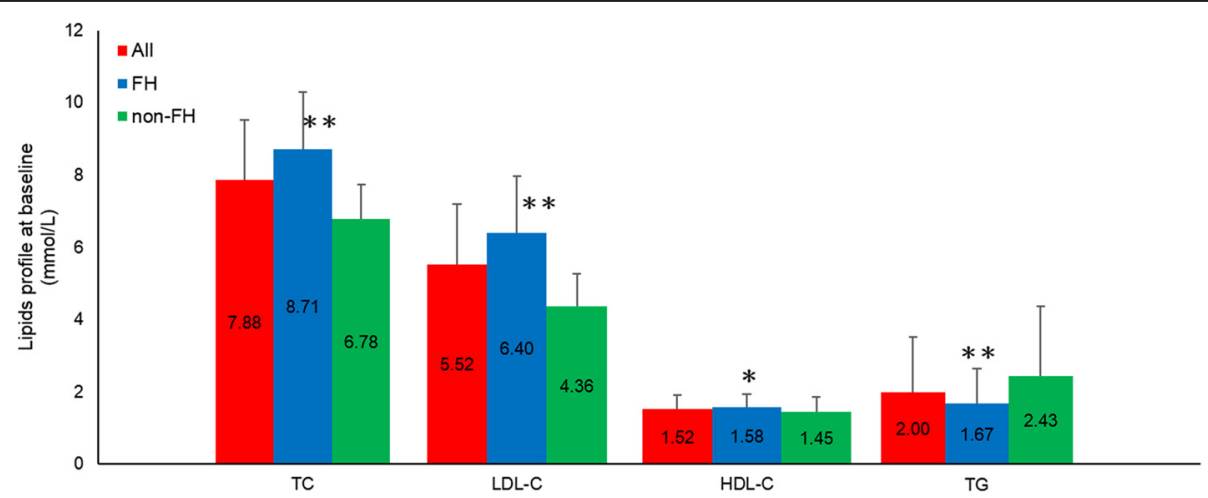

Fig. 1 Baseline lipid profiles on no lipid-lowering treatment in study subjects. Data are given as mean and error bars represent $S D ;{ }^{*} P<0.005 ;{ }^{*}$ $P<0.001$ for $\mathrm{FH}$ vs. non-FH 


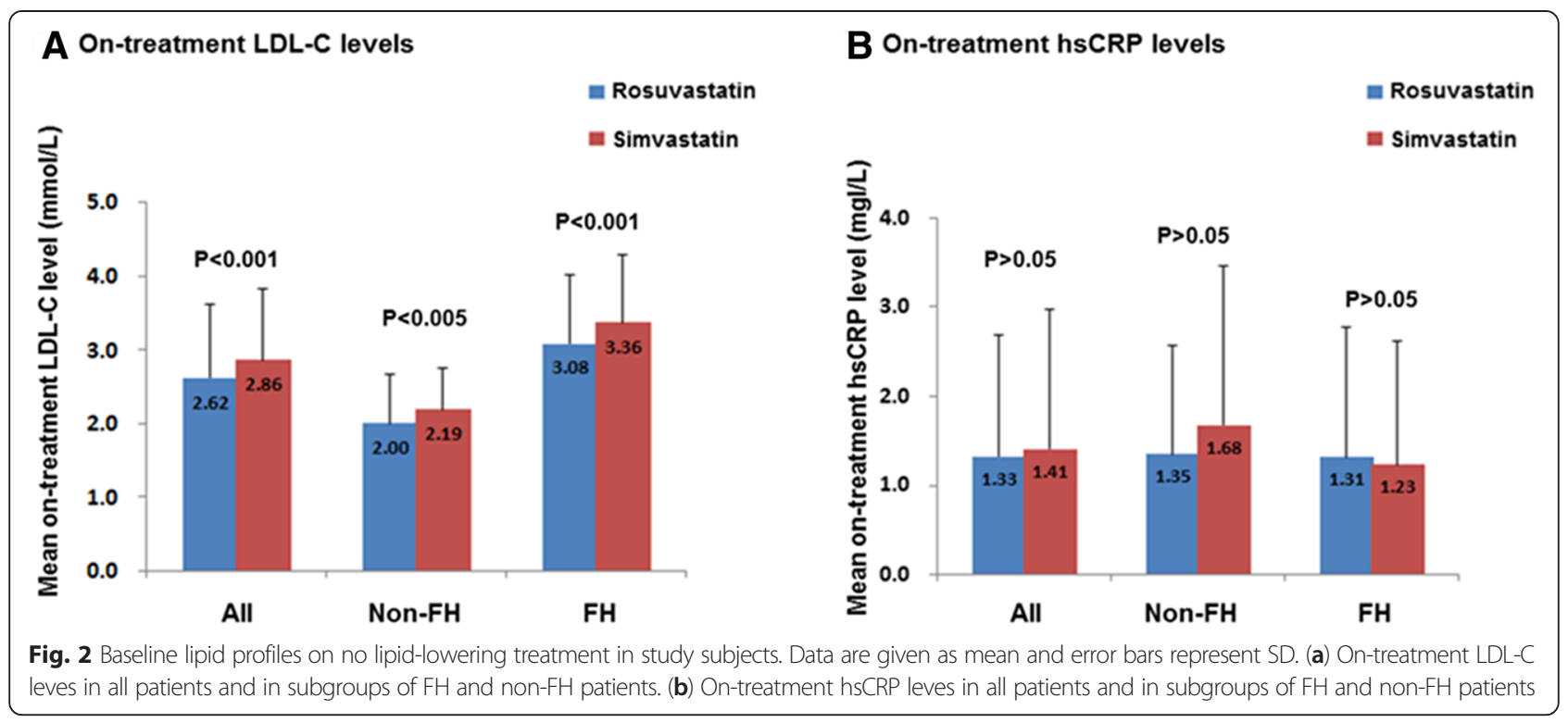

had similar effects on the reductions in both LDL-C and hs-CRP and the combination of simvastatin $10 \mathrm{mg}$ with ezetimibe $10 \mathrm{mg}$ also produced similar responses [21]. That finding may suggest that there is less difference in the effects of these doses of the two statins on LDL-C in Caucasians than in Chinese, which would be compatible with the known ethnic differences in rosuvastatin pharmacokinetics [22]. However, recent data from the VOYAGER meta-analysis suggested that $10 \mathrm{mg}$ rosuvastatin is equivalent to approximately $70 \mathrm{mg}$ simvastatin for the effect on LDL-C [23].

Our results showed that there were $57.1 \%$ of patients having an on-treatment hsCRP level of $<1 \mathrm{mg} / \mathrm{L}$ with both of the statins and only $25.4 \%$ and $19.9 \%$ of patients had hsCRP levels $\geq 2 \mathrm{mg} / \mathrm{L}$ with rosuvastatin and simvastatin, respectively $(P>0.05)$. The hsCRP goal attainment was comparable between patients with or without $\mathrm{FH}$ and is greater than in patients in western countries [24], which is probably due to a lower baseline hsCRP levels in East Asian populations such as Japanese and Chinese [25]. Baseline hsCRP levels are largely determined by genetic factors and obesity and both may contribute to the ethnic differences in baseline hsCRP levels [26]. In a populationbased prospective cohort study in a general Japanese population, higher hsCRP levels were significantly associated with a higher incidence of future CHD events even
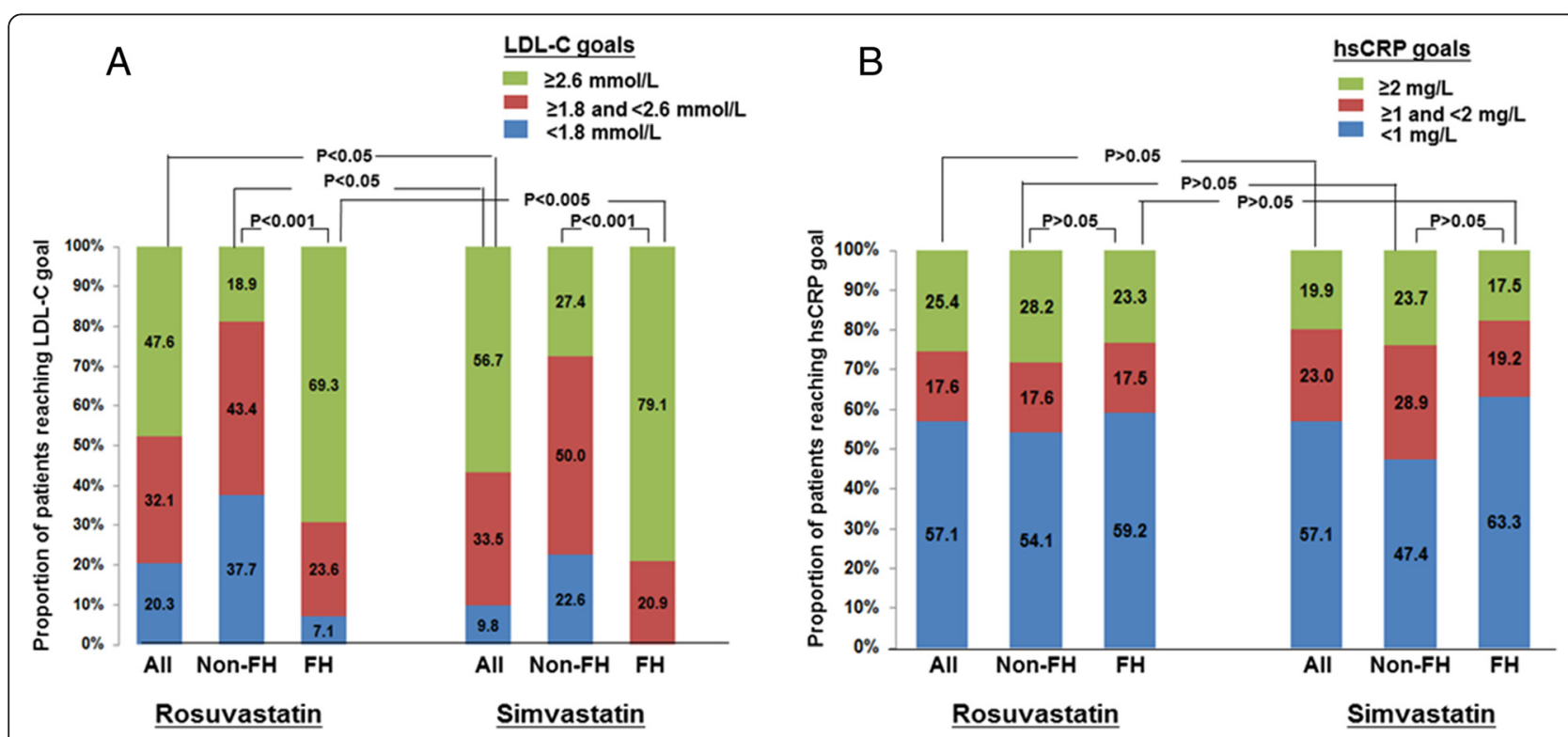

Fig. 3 Proportion of subjects with on-treatment LDL-C of $<2.6$ and $<1.8 \mathrm{mmol} / \mathrm{L}$ (a) and hsCRP $<2$ and $<1 \mathrm{mg} / \mathrm{L}$ (b) with the two statins 
when the hsCRP level was below $1 \mathrm{mg} / \mathrm{L}$ [27]. Adiposity, especially abdominal obesity, is the strongest predictor of hsCRP concentrations across different populations [25], probably resulting from obesity-induced up-regulation of the cytokines IL- 6 and TNF- $\alpha$ which contributes to lowgrade inflammatory and hsCRP elevation [28]. As Asians have lower cutoff-points for waist circumference and body mass index to define obesity and metabolic syndrome, as recommended by the World Health Organisation [29], it may also be appropriate to have lower hsCRP goals in these East Asian populations.

Current evidence suggests that there is no relationship between the reductions in LDL-C and in hsCRP in response to the statin treatments in individual patients $[14,30,31]$. Similar results were found in Japanese patients treated with pitavastatin [32], and also with atorvastatin [33]. However, a previous meta-analysis which did not include the JUPITER trial demonstrated a strong relationship between average changes in LDL-C and CRP $(r=0.80, P<0.001)$ in healthy subjects and subjects with stable coronary artery disease who were treated with LDL-lowering interventions in placebocontrolled trials [34], but this meta-analysis was performed using mean levels of LDL-C and CRP changes in each trial and this may not reflect the true correlation between the changes in LDL-C and CRP in individuals. Another study from Greece demonstrated correlations between CRP reduction and the lipid-lowering effects of simvastatin within Caucasian patients who were receiving chronic haemodialysis [35], but they may represent an unusual group. The present study did not examine the correlation between the changes in LDL-C and hsCRP in response to the two statins as the baseline hsCRP level was not available which is one of the main limitations of the study. However, the stronger correlation between the LDL-C values on the two statin treatments compared to that between the hsCRP values on the two statin treatments and the wide range of hsCRP values on statin treatments suggests that the hsCRP changes with statin treatments are more variable than the LDL-C changes.

In contrast to achieving maximum lipid-lowering effect after at least 4 weeks treatment, statins appear to exert anti-inflammatory and beneficial endothelial effects more rapidly, even after a single dose [36]. For instance, a single $80 \mathrm{mg}$ loading dose of atorvastatin within $24 \mathrm{~h}$ of percutaneous coronary intervention reduced the incidence of peri-procedural myocardial infarction [37]. Our previous data showed that the $A B C G 2421 \mathrm{C}>\mathrm{A}$ polymorphism plays an important role in determining the on-treatment level and LDL-C response to rosuvastatin in Chinese patients but this polymorphism had no effect on the hsCRP on-treatment levels in this group of subjects $[26,38]$. The recent genome-wide analysis in over 3000 subjects of European ancestry who had been randomly allocated to rosuvastatin $20 \mathrm{mg}$ or placebo daily in the JUPITER study also confirmed that a polymorphism (rs1481012) in $A B C G 2$ which is in nearly complete linkage disequilibrium (LD) with the $A B C G 2$ $421 \mathrm{C}>$ A polymorphism was the only pharmacokineticrelated variant significantly associated on a genomewide basis with the LDL-C reduction in response to rosuvastatin [39]. This genetic polymorphism together with several other polymorphisms associated with the LDL-C response to rosuvastatin identified in the JUPITER study had no impact on the rosuvastatin-induced hsCRP reduction after correction for multiple testing [40]. This result further supports the hypothesis that statin-mediated effects on inflammation as measured by hsCRP are independent of statin-mediated effects on LDL-C and less influenced by the statin pharmacokinetics.

Some clinical studies showed that higher doses of statins may reduce the hsCRP levels more than lower doses of statins in patients with diabetes or stable coronary disease $[41,42]$. However, our study and the JUPITER study showed that patients with the ABCG2 421A variant allele with increased systemic exposure to rosuvastatin had similar hsCRP on-treatment level or hsCRP reduction in response to rosuvastatin as those patients without the variant allele suggesting that some other genetic and/or environmental factors may affect the hsCRP lowering effect in response to statins. The dosage of statins used in our study might be considered as relatively high in some Asian countries. However, previous studies in Japan have shown that rosuvastatin $10 \mathrm{mg}$ results in reductions in LDL-C of approximately $50 \%$ which is similar to our study [43, 44]. In the STELLAR Trial, which compared different doses of rosuvastatin and other statins, the LDL-C reduction with rosuvastatin $10 \mathrm{mg}$ was $45.8 \%$ and with simvastatin $40 \mathrm{mg}$ was $38.8 \%$ in a mainly Caucasian Group [45]. These values are both less than the LDL-C reductions seen in the Hong Kong patients, probably because the STELLAR Trial used an intention to treat analysis whereas the Hong Kong patients were selected for having good compliance with therapy. Furthermore, it was shown that this degree of LDL-C reduction is needed to achieve regression of coronary atheroma in Japanese patients [17].

The present study showed there was no difference in hsCRP levels with the two statins with different potency in reducing LDL-C levels in this patient group. Rosen et al. have reported that although switching to ezetimibe/ simvastatin $(10 / 20 \mathrm{mg})$ was more effective at reducing LDL-C vs. doubling the baseline statin dose to simvastatin $40 \mathrm{mg}$ or atorvastatin $20 \mathrm{mg}$ or switching to rosuvastatin $10 \mathrm{mg}$, the combination therapy was not superior to statin monotherapy in reducing hsCRP [46]. Interestingly, another study demonstrated that despite having similar lipid-lowering potency, atorvastatin $10 \mathrm{mg}$ 
resulted in greater reductions hsCRP and its variability compared with simvastatin $40 \mathrm{mg}$ in type 2 diabetic patients [47]. It has been shown that treatment with highdose (80 mg daily) atorvastatin for 2 weeks had no effect on hsCRP levels in normolipidaemic subjects with normal hsCRP levels although the LDL-C levels were significantly reduced indicating baseline hsCRP levels may play an important role in determining the statin-mediated hsCRP reduction [48].

\section{Conclusions}

In conclusion, this study showed that a significantly greater proportion of patients achieved LDL-C targets with rosuvastatin $10 \mathrm{mg}$ compared to simvastatin $40 \mathrm{mg}$ in Chinese patients with or without $\mathrm{FH}$, but there was no difference in hsCRP levels with the two statin treatments with the majority of patients reaching hsCRP levels of $<2 \mathrm{mg} / \mathrm{L}$. The study also suggested that more intensive lipid-lowering treatments are needed to enable more $\mathrm{FH}$ patients to reach their LDL-C goals.

\section{Competing interests}

Brian Tomlinson has received research funding to perform clinical studies from AstraZeneca, Bayer, Boehringer Ingelheim, Daiichi Sankyo, Kowa, Merck Serono, Merck Sharp and Dohme, Novartis, Otsuka, Pfizer, Roche, Sanofi-Aventis and Servier and has acted as a consultant or speaker on occasions for AstraZeneca, Bayer, Boehringer Ingelheim, Bristol-Myers Squibb, GlaxoSmithKline, Kowa, Merck Serono, Merck Sharp and Dohme, Novartis, Pfizer, Roche, Sanofi-Aventis, Schering-Plough, and Servier. The other authors have no conflict of interests.

\section{Authors' contribution}

CD helped to analyses the data and draft the manuscript. YJW reviewed/ edited the manuscript. MH and BT designed and conducted the research, performed data analysis and interpretation, and helped to draft and edit the manuscript. All authors have approved the final version of the article.

\section{Acknowledgments}

The work described in this paper was substantially supported by a grant from the Research Grants Council of the Hong Kong Special Administrative Region, China (Project no. CUHK 4472/06 M). This funding source had no role in the conduct of the study. The authors would like to thank Ms. Evelyn Chau for her assistance in patient recruitment. No writing assistance was utilized in the production of this manuscript.

\section{Author details}

'State Key Laboratory of Cardiovascular Disease, Department of Cardiology, Cardiovascular Institute, Fuwai Hospital and National Center for Cardiovascular Diseases, Chinese Academy of Medical Sciences \& Peking Union Medical College, Beijing, China. ${ }^{2}$ Department of Medicine and Therapeutics, The Chinese University of Hong Kong, Prince of Wales Hospital, Shatin, Hong Kong.

Received: 24 August 2015 Accepted: 4 September 2015

Published online: 13 September 2015

\section{References}

1. Athyros VG, Kakafika Al, Tziomalos K, Karagiannis A, Mikhailidis DP. Pleiotropic effects of statins-clinical evidence. Curr Pharm Des. 2009;15(5):479-89.

2. Blum A, Shamburek R. The pleiotropic effects of statins on endothelial function, vascular inflammation, immunomodulation and thrombogenesis. Atherosclerosis. 2009;203(2):325-30.

3. Baigent C, Keech A, Kearney PM, Blackwell L, Buck G, Pollicino C, et al. Efficacy and safety of cholesterol-lowering treatment: prospective meta-analysis of data from 90,056 participants in 14 randomised trials of statins. Lancet. 2005;366(9493):1267-78.
4. Baigent C, Blackwell L, Emberson J, Holland LE, Reith C, Bhala N, et al. Efficacy and safety of more intensive lowering of LDL cholesterol: a meta-analysis of data from 170,000 participants in 26 randomised trials. Lancet. 2010;376(9753):1670-81.

5. De Backer G, Ambrosioni E, Borch-Johnsen K, Brotons C, Cifkova R, Dallongeville J, et al. European guidelines on cardiovascular disease prevention in clinical practice. Third Joint Task Force of European and Other Societies on Cardiovascular Disease Prevention in Clinical Practice. Eur Heart J. 2003;24(17):1601-10.

6. Expert Panel on Detection Evaluation and Treatment of High Blood Cholesterol in Adults. Third Report of the National Cholesterol Education Program (NCEP) Expert Panel on Detection, Evaluation, and Treatment of High Blood Cholesterol in Adults (Adult Treatment Panel III) final report. Circulation. 2002;106(25):3143-421.

7. Grundy SM, Cleeman JI, Merz CN, Brewer Jr HB, Clark LT, Hunninghake DB, et al. Implications of recent clinical trials for the National Cholesterol Education Program Adult Treatment Panel III guidelines. Circulation. 2004;110(2):227-39.

8. Libby P, Ridker PM. Inflammation and atherosclerosis: role of C-reactive protein in risk assessment. Am J Med. 2004;116(Suppl 6A):9S-16.

9. Hansson GK, Libby P. The immune response in atherosclerosis: a double-edged sword. Nat Rev Immunol. 2006;6(7):508-19.

10. Kaptoge S, Di Angelantonio E, Lowe G, Pepys MB, Thompson SG, Collins R, et al. C-reactive protein concentration and risk of coronary heart disease, stroke, and mortality: an individual participant meta-analysis. Lancet. 2010;375(9709):132-40.

11. Nordestgaard $B G$, Zacho J. Lipids, atherosclerosis and CVD risk: is CRP an innocent bystander? Nutr Metab Cardiovasc Dis. 2009;19(8):521-4.

12. Nissen SE, Tuzcu EM, Schoenhagen P, Crowe T, Sasiela WJ, Tsai J, et al. Statin therapy, LDL cholesterol, C-reactive protein, and coronary artery disease. N Engl J Med. 2005;352(1):29-38.

13. Ridker PM, Cannon CP, Morrow D, Rifai N, Rose LM, McCabe $\mathrm{CH}$, et al. C-reactive protein levels and outcomes after statin therapy. N Engl J Med. 2005;352(1):20-8.

14. Ridker PM, Danielson E, Fonseca FA, Genest J, Gotto Jr AM, Kastelein JJ, et al. Reduction in C-reactive protein and LDL cholesterol and cardiovascular event rates after initiation of rosuvastatin: a prospective study of the JUPITER trial. Lancet. 2009;373(9670):1175-82.

15. Food and Drug Administration. Questions and Answers for Healthcare Professionals: CRESTOR and the JUPITER Trial. Feburary 8 2010. Available at :http://www.fda.gov/Drugs/DrugSafety/PostmarketDrugSafetylnformationfor PatientsandProviders/ucm 199891.htm Accessed on 6 September 2012. 2010.

16. Robinson JG, Ballantyne CM, Hsueh WA, Rosen JB, Lin J, Shah AK, et al. Age, abdominal obesity, and baseline high-sensitivity C-reactive protein are associated with low-density lipoprotein cholesterol, non-high-density lipoprotein cholesterol, and apolipoprotein B responses to ezetimibe/ simvastatin and atorvastatin in patients with metabolic syndrome. J Clin Lipidol. 2013;7(4):292-303.

17. Arai H, Hiro T, Kimura T, Morimoto T, Miyauchi K, Nakagawa Y, et al. More intensive lipid lowering is associated with regression of coronary atherosclerosis in diabetic patients with acute coronary syndrome-sub-analysis of JAPAN-ACS study. J Atheroscler Thromb. 2010;17(10):1096-107.

18. Hu M, Mak WW, Tomlinson B. Intronic variants in SLCO1B1 related to statin-induced myopathy are associated with the low-density lipoprotein cholesterol response to statins in Chinese patients with hyperlipidaemia. Pharmacogenet Genomics. 2012;22(11):803-6.

19. Jones PH, Hunninghake DB, Ferdinand KC, Stein EA, Gold A, Caplan RJ, et al. Effects of rosuvastatin versus atorvastatin, simvastatin, and pravastatin on non-high-density lipoprotein cholesterol, apolipoproteins, and lipid ratios in patients with hypercholesterolemia: additional results from the STELLAR trial. Clin Ther. 2004;26(9):1388-99.

20. Watts GF, Gidding S, Wierzbicki AS, Toth PP, Alonso R, Brown W, et al. Integrated guidance on the care of familial hypercholesterolaemia from the International FH Foundation: executive summary. J Atheroscler Thromb. 2014;21(4):368-74.

21. Moutzouri E, Liberopoulos E, Mikhailidis DP, Kostapanos MS, Kei AA, Milionis H, et al. Comparison of the effects of simvastatin vs. rosuvastatin vs. simvastatin/ ezetimibe on parameters of insulin resistance. Int J Clin Pract. 2011;65(11):1141-8.

22. Hu M, Lui SS, Ko GT, Tomlinson B. Do the lipid responses to rosuvastatin and atorvastatin differ between Chinese and Caucasians? Comparison of the DISCOVERY-Hong Kong study with other DISCOVERY studies. Int J Cardiol. 2013;168(3):3071-3. 
23. Karlson BW, Palmer MK, Nicholls SJ, Lundman P, Barter PJ. Doses of rosuvastatin, atorvastatin and simvastatin that induce equal reductions in LDL-C and non-HDL-C: Results from the VOYAGER meta-analysis. Eur J Prev Cardiol. 2015. pii: 2047487315598710. [Epub ahead of print]

24. Chiang CW, Santos RD, Waters DD, Messig M, Tarasenko L, Jukema JW, et al. Reaching C-reactive protein and low-density lipoprotein cholesterol goals in dyslipidemic patients (from the Lipid Treatment Assessment Project [L-TAP] 2). Am J Cardiol. 2011:107(11):1639-43.

25. Kelley-Hedgepeth A, Lloyd-Jones DM, Colvin A, Matthews KA, Johnston J, Sowers MR, et al. Ethnic differences in C-reactive protein concentrations. Clin Chem. 2008;54(6):1027-37.

26. Hu M, Lee MH, Mak WW, Tomlinson B. Effect of Central Obesity, Low High-Density Lipoprotein Cholesterol and C-Reactive Protein Polymorphisms on C-Reactive Protein Levels During Treatment With Rosuvastatin (10 mg Daily). Am J Cardiol. 2010;106(11):1588-93.

27. Arima H, Kubo M, Yonemoto K, Doi Y, Ninomiya T, Tanizaki Y, et al. High-sensitivity C-reactive protein and coronary heart disease in a general population of Japanese: the Hisayama study. Arterioscler Thromb Vasc Biol. 2008;28(7):1385-91.

28. Van Gaal LF, Mertens IL, De Block CE. Mechanisms linking obesity with cardiovascular disease. Nature. 2006;444(7121):875-80.

29. Tomlinson B, Deng HB, Thomas GN. Prevalence of obesity amongst Chinese populations revisited. Future Lipidol. 2008;3(2):139-52

30. Ridker PM, Rifai N, Rose L, Buring JE, Cook NR. Comparison of C-reactive protein and low-density lipoprotein cholesterol levels in the prediction of first cardiovascular events. N Engl J Med. 2002;347(20):1557-65.

31. Albert MA, Danielson E, Rifai N, Ridker PM, Investigators P. Effect of statin therapy on C-reactive protein levels - The Pravastatin Inflammation/CRP Evaluation (PRINCE): A randomized trial and cohort study. Jama-J Am Med Assoc. 2001;286(1):64-70

32. Koshiyama H, Taniguchi A, Tanaka K, Kagimoto S, Fujioka Y, Hirata K, et al. Effects of pitavastatin on lipid profiles and high-sensitivity CRP in Japanese subjects with hypercholesterolemia: Kansai Investigation of Statin for Hyperlipidemic Intervention in Metabolism and Endocrinology (KISHIMEN) investigatars. J Atheroscler Thromb. 2008;15(6):345-50.

33. Yamada S, Yanagawa T, Sasamoto K, Araki A, Miyao M, Yamanouchi T. Atorvastatin lowers plasma low-density lipoprotein cholesterol and C-reactive protein in Japanese type 2 diabetic patients. Metabolism. 2006;55(1):67-71.

34. Kinlay S. Low-density lipoprotein-dependent and -independent effects of cholesterol-lowering therapies on C-reactive protein: a meta-analysis. J Am Coll Cardiol. 2007;49(20):2003-9.

35. Kirmizis D, Papagianni A, Dogrammatzi F, Skoura L, Belechri AM, Alexopoulos $E$, et al. Effects of simvastatin on markers of inflammation oxidative stress and endothelial cell apoptosis in patients on chronic hemodialysis. J Atheroscler Thromb. 2010;17(12):1256-65.

36. Li JJ, Wang Y, Nie SP, Zhang CY, Li YS, Hui RT, et al. Reduction of C-reactive protein by a single $80 \mathrm{mg}$ of simvastatin in patients with unstable angina. Clin Chim Acta. 2007;376(1-2):163-7.

37. Briguori C, Visconti G, Focaccio A, Golia B, Chieffo A, Castelli A, et al. Nove approaches for preventing or limiting events (Naples) II trial: impact of a single high loading dose of atorvastatin on periprocedural myocardial infarction. J Am Coll Cardiol. 2009;54(23):2157-63.

38. Tomlinson B, Hu M, Lee WW, Lui SS, Chu TT, Poon EW, et al. ABCG2 polymorphism is associated with the low-density lipoprotein cholesterol response to rosuvastatin. Clin Pharmacol Ther. 2010;87(5):558-62.

39. Chasman DI, Giulianini F, MacFadyen J, Barratt BJ, Nyberg F, Ridker PM. Genetic determinants of statin-induced low-density lipoprotein cholesterol reduction: the Justification for the Use of Statins in Prevention: an Intervention Trial Evaluating Rosuvastatin (JUPITER) trial. Circ Cardiovasc Genet. 2012;5(2):257-64.

40. Chu AY, Guilianini F, Barratt BJ, Nyberg F, Chasman DI, Ridker PM. Pharmacogenetic determinants of statin-induced reductions in C-reactive protein. Circ Cardiovasc Genet. 2012;5(1):58-65.

41. Bonnet J, McPherson R, Tedgui A, Simoneau D, Nozza A, Martineau P, et al. Comparative effects of $10-\mathrm{mg}$ versus $80-\mathrm{mg}$ Atorvastatin on high-sensitivity C-reactive protein in patients with stable coronary artery disease: results of the CAP (Comparative Atorvastatin Pleiotropic effects) study. Clin Ther. 2008;30(12):2298-313.

42. Betteridge DJ, Gibson JM, Sager PT. Comparison of effectiveness of rosuvastatin versus atorvastatin on the achievement of combined C-reactive protein $(<2 \mathrm{mg} / \mathrm{L})$ and low-density lipoprotein cholesterol $(<70 \mathrm{mg} / \mathrm{dl})$ targets in patients with type 2 diabetes mellitus (from the ANDROMEDA study). Am J Cardiol. 2007;100(8):1245-8.

43. Mabuchi H, Nohara A, Higashikata T, Ueda K, Bujo H, Matsushima T, et al. Clinical efficacy and safety of rosuvastatin in Japanese patients with heterozygous familial hypercholesterolemia. J Atheroscler Thromb. 2004;11(3):152-8.

44. Saito Y, Goto Y, Dane A, Strutt K, Raza A. Randomized dose-response study of rosuvastatin in Japanese patients with hypercholesterolemia. J Atheroscler Thromb. 2003;10(6):329-36.

45. Jones PH, Davidson MH, Stein EA, Bays HE, McKenney JM, Miller E, et al. Comparison of the efficacy and safety of rosuvastatin versus atorvastatin simvastatin, and pravastatin across doses (STELLAR* Trial). Am J Cardiol. 2003;92(2):152-60

46. Rosen JB, Jimenez JG, Pirags V, Vides $H$, Massaad R, Hanson ME, et al. Consistency of effect of ezetimibe/simvastatin compared with intensified lipid-lowering treatment strategies in obese and non-obese diabetic subjects. Lipids Health Dis. 2013;12:103.

47. Sathyapalan T, Atkin SL, Kilpatrick ES. Disparate effects of atorvastatin compared with simvastatin on C-reactive protein concentrations in patients with type 2 diabetes. Diabetes Care. 2010;33(9):1948-50.

48. Millar JS, Ky B, Wolfe ML, Pruscino L, Baer A, Rader DJ. Short-term treatment with high-dose atorvastatin reduces LDL cholesterol but shows no anti-inflammatory effects in normolipidemic subjects with normal CRP levels. Clin Transl Sci. 2010;3(4):140-6.

\section{Submit your next manuscript to BioMed Central and take full advantage of:}

- Convenient online submission

- Thorough peer review

- No space constraints or color figure charges

- Immediate publication on acceptance

- Inclusion in PubMed, CAS, Scopus and Google Scholar

- Research which is freely available for redistribution 